Table 1. Values of $P(E / S)$, the Probability that an Event of TYPE $E$ IS PRODUCED BY A SHOWRR OF TYPE $S$

\begin{tabular}{l|l|l|l|l|l|}
\hline & $S_{1}$ & $S_{2}$ & $S_{3}$ & $S_{4}$ & \multicolumn{1}{|c|}{$S_{\mathrm{B}}$} \\
\hline$E_{1}$ & $0 \cdot 8$ & $0 \cdot 1$ & 0 & 0 & 0 \\
$E_{3}$ & $0 \cdot 2$ & $0 \cdot 8$ & $0 \cdot 1$ & 0 & 0 \\
$E_{3}$ & 0 & $0 \cdot 1$ & $0 \cdot 8$ & $0 \cdot 1$ & 0 \\
$\boldsymbol{E}_{3}$ & 0 & 0 & $0 \cdot 1$ & $0 \cdot 8$ & $0 \cdot 2$ \\
$E_{3}$ & 0 & 0 & 0 & $0 \cdot 1$ & $0 \cdot 8$ \\
\hline
\end{tabular}

Then according to the standard theory of maximum likelihood, one would ascribe an event $E_{1}$ to a shower of type $S_{1}$, an $E_{2}$ to an $S_{2}$, and so on, and would say that in this description each shower had an 80 per cent chance of being correctly typed. If now we convert the above probability distribution into the corresponding frequency distribution, we obtain the following (Table 2):

Table 2. Frequency Distribution Derived from Table 1

\begin{tabular}{|c|r|r|r|r|r|}
\hline & \multicolumn{1}{|c|}{$S_{1}$} & $S_{2}$ & $S_{3}$ & $S_{4}$ & $S_{5}$ \\
\hline$E_{1}$ & 80,000 & 1,000 & 0 & 0 & 0 \\
$E_{2}$ & 20,000 & 8,000 & 100 & 0 & 0 \\
$E_{3}$ & 0 & 1,000 & 800 & 10 & 0 \\
$E_{4}$ & 0 & 0 & 100 & 80 & 2 \\
$E_{5}$ & 0 & 0 & 0 & 10 & 8 \\
\hline
\end{tabular}

It will be seen that, while the most probable cause of an event of type $E_{1}$ is still a shower of type $S_{1}$, the most probable cause of an event $E_{2}$ is again a shower of type $S_{1}$, not $S_{2}$. Again, the normal maximum likelihood method would ascribe an event $E_{3}$ to a shower $S_{3}$ and claim 80 per cent probability of being correct. It will be observed, however, that of all the events of type $E_{3}$ recorded, only 44 per cent are produced by $S_{3}$ showers; the majority of them are, in fact, produced by $S_{2}$ showers.

The chances of correct assignment for $E_{1}$ events, which we may reasonably identify with events failing to trigger the apparatus, is 98.8 per cent, but the chances of correct assignment for all other types of events averages only 30 per cent. Thus, if, as is certainly the case, a very numerous class of small showers has a low triggering probability, the frequency of success of the standard method in analysing observed events drops from 80 to 30 per cent.

It will be seen, therefore, that if some classes of showers are vastly more numerous than others, as is the case, and if the probability distribution $P(E / S)$, the probability that an $S$-type shower will produce an $E$-type event, is not sharply peaked, then some account must be taken of the a priori probability of occurrence of the $S$-type shower, $P(S)$, in order to avoid a consistent over-estimate of the shower size. This has been done in the analysis of the air shower data by using Bayes's Theorem ${ }^{6}$ :

$$
P(S / E)=P(E / S) P(S) / P(E)
$$

The quantity $P(S / E)$ can be meaningfully interpreted only as a relative frequency of the type discussed above. Such an interpretation is not strictly admissible in our case, since we would very rarely indeed see even two events of the same type. However, investigation of the form of the function $P(S / E)$ as a function of $S$ for various different events $E$ has shown that large numbers of events are sufficiently similar to justify the use of this quantity.

It should also be pointed out that we cannot claim freedom from bias in the determination of any quantity which we may wish to estimate about a shower using the analysis programme described. If, for each shower, we had been concerned to find the most probable value of $N$, the shower size, without at the same time requiring to know the core location, then we should maximize $P(N / E)$ defined as :

$$
P(N / E)=\int_{-\infty}^{\infty} \int_{-\infty}^{\infty} P(S / E) d X d Y
$$

This has, in fact, been done by us for a sample of showers as has been mentioned, and the best value of $N$ so determined is, in general, greater by about 5 per cent than is the value computed in the normal analysis. One should, in fact, maximize the probability distribution of whatever single physical result is desired such as shower size, core location, density of particles at a particular detector, and so on. Such a course is, however, impracticable because of the volume of computation involved. The calculations mentioned above for finding the most probable value of $N$ independent of the core location $(X, Y)$, and for finding the probability distribution in the core location consumed some $10-50 \mathrm{~min}$. of machine time per event analysed.

1 Greisen, K. " Progress in Cosmic Ray Physics", 3, Chapter 1 (North Holland Pub. Co., Amsterdam, 1956).

2 Proceedings of the IUPAP Cosmic Ray Conference, Varenna (1957). To be published as a Supplement to Il Nuovo Cimento.

${ }^{3}$ Brennan, M. H., Nuovo Cim., 6, 216 (1957).

- Bassi, P., Clark, G., and Rossi, B., Phys. Rev., 92, 441 (1953).

${ }^{s}$ Clark, G., Earl, J., Kraushaar, W., Linsley, J., Rossi, B., and Scherb, F., Nature, 180, 353, 406 (1957).

'Annis, M., Cheston, W., and Primakoff, H., Rev. Mod. Phys., 25, 818 (1953).

"Kendall, M. G., "The Advanced Theory of Statistics", 2 (Charles Griffin and Co., London, 1946).

\title{
LIFE AT LOW TEMPERATURES
}

$I^{N}$ recent decades man has been striving for mastery of chemical, physical and climatic forces, however abstruse or remote from his usual environment. Such mastery, when achieved, would be ineffectual or even dangerous if the biological effects of the same forces had been ignored, either in their impacts on individual plants and animals or in their widest ecological significance. During the past year, temperatures lower than any hitherto recorded in the range below $1^{\circ} \mathrm{K}$. have been produced by adiabatic demagnetization and their effects on the properties of matter have been studied. During the same period, Antaretica has been crossed above and the North Pole below its ice cap. It was therefore appropriate that the British Association should hold a joint session of Sections D and I. (Zoology and Physiology) on August 28 to discuss life at low temperatures.

Dr. K. Mellanby emphasized that insects of a large group are killed at temperatures above freezing point and become comatose from cold before there is danger of death. Self-protective responses and development are inhibited when their surroundings are comparatively warm. Many insects would be incapable both of completing their life-cycles and of avoiding extermination unless the environmental temperatures were well above zero for a considerable period each 
year. Such insects become rapidly acclimatized by brief exposure to a slightly colder environment. Thus, the chill-coma temperature of cockroaches kept at $30^{\circ} \mathrm{C}$. is $7.5^{\circ} \mathrm{C}$, but when individuals from the same stock are kept at $15^{\circ} \mathrm{C}$. for as little as $24 \mathrm{hr}$. they afterwards move actively at $2^{\circ} \mathrm{C}$. Similarly, the alarm reaction of larva of the yellow fever mosquito (Aedes aegypti) can be elicited at lower temperatures after exposing them for $24 \mathrm{hr}$. to colder water. The processes of acclimatization in insects are rapidly reversible, and their underlying mechanism remains a mystery. Insects of a second large group survive exposure to temperatures below freezing point provided that they remain supercooled. Crystallization of ice in their tissues is fatal to them. The degree to which they can be supercooled depends on the duration of exposure to that temperature. It also depends on the water content of the tissues and of the material in the gut. No material exists more water-proof than insect cuticle. Nevertheless, when a drop of moisture freezes on the outer surface of a supercooled insect the tissue fluids beneath the cuticle are instantly inoculated with ice and freeze. Recently, Asahina and Aoki ${ }^{1}$ reported that certain moth larvæ survived freezing in liquid air under conditions in which the greater part of their body. water was converted into crystals of ice situated outside the individual cells composing the tissues. Dr. Mellanby pointed out that, from an ecological point of view, liquid air is not an important habitat. On the other hand, witnesses of the advent of spring in the Arctic describe the abundance of active insects before the snow has melted sufficiently to uncover sheltered spots with warmer micro-climates ${ }^{2}$. The third group of insects which survive freezing at low temperatures may, therefore, be larger and more important than hitherto supposed.

Rome and Cape Cod are at approximately the same latitude $\left(42^{\circ}\right)$. It was therefore surprising to learn from Dr. J. W. Kanwisher that temperatures between $-15^{\circ}$ and $-30^{\circ} \mathrm{C}$. are frequently recorded on the shore at Woods Hole in winter. The intertidal molluses are in open air for $6 \mathrm{hr}$. or more around low tide twice each day. When not covered by sea water the internal temperatures of oysters, mussels and periwinkles are almost identical with the atmospheric temperature. At $-15^{\circ}$ C., 60-85 per cent of the water in the bodies of these molluses was frozen. Nevertheless, intact molluscs of the same species recovered fully when thawed after freezing to the same extent. Histological sections of tissues from the frozen animals showed remarkable distortion of the muscles and of the internal organs by ice crystals situated outside the cells which were shrunken. Within a few seconds of thawing the microscopic anatomy was normal. When water crystallized as ice the tissues were exposed to increased salinity, reaching a maximum at $-20^{\circ} \mathrm{C}$. The tissues of the intertidal molluses became isosmotic with concentrated solutions of salt to which they were exposed experimentally. A change in temperature of $10 \mathrm{deg}$. C. altered their oxygen consumption by a factor of 2 in the range above $0^{\circ} \mathrm{C}$. and by 50 below $0^{\circ} \mathrm{C}$. An increase in the salt concentration above zero equivalent to the increased salinity of partially frozen sea water cooled by $10 \mathrm{deg}$. C. reduced the oxygen consumption of the molluscs by a factor between 10 and 20. The striking alteration in the $Q_{10}\left(\mathrm{O}_{2}\right)$ of the frozen animals cannot, therefore, be entirely explained by the combined effects of raised salinity and reduced temperature. Decreased diffusion of gases and increased viscosity of residual tissue fluids may also be involved. Many molluscs are immobile at $0^{\circ} \mathrm{C}$. Some teleost fish, on the other hand, swim in Arctic waters at a temperature which remains steadily at $-1 \cdot 7^{\circ} \mathrm{C}$. at the bottom and fluctuates near the surface between $-1 \cdot 7^{\circ} \mathrm{C}$. below the ice in winter and $+7^{\circ} \mathrm{C}$. after the ice has melted in summer. The freezing point of blood from teleosts in temperate waters is between $-0.5^{\circ} \mathrm{C}$. and $-0 \cdot 8^{\circ} \mathrm{C}$. The freezing point of plasma from five species of deep-water Arctic fish was between $-0.9^{\circ}$ and $-1.0^{\circ} \mathrm{C}$. These fish were actively swimming with their tissue fluids in the supercooled state. They were in no danger of being seeded with ice crystals in their own ecological niche, but when brought near the surface on which ice was floating they soon froze throughout and perished. By contrast, the plasma of the Arctic surface fish froze at $-0.8^{\circ} \mathrm{C}$. in summer and at $-1.5^{\circ} \mathrm{C}$. in winter. The osmotic concentration of their body fluids had doubled before winter set in, so that they became supercooled by less than $0 \cdot 4 \mathrm{deg}$. C. The risk of freezing was thus reduced when ice formed nearby. Dr. Kanwisher's demonstration that animals can retain full activity in the supercooled state has introduced a new conception into low-temperature ecology.

The practice of storing semen in the frozen state at low temperatures is no longer new. Nine years have passed since the report was published that glycerol protected avian spermatozoa against damage during freezing and thawing ${ }^{3}$. Seven years ago the possibility of banking glycerol-treated frozen bull semen was discussed at the British Association. Since then the technique has been adopted at every major cattle-breeding centre where artificial insemination is practised. A review by Dr. C. Polge, the leading authority on the subject, was therefore welcome. He said that it was essential to restore the motility of a high proportion of spermatozoa in semen to be inseminated after freezing to and storage at low temperatures. Dilution to contain a suitable concentration of glycerol and a slow rate of cooling are the two procedures vital for preserving sperm from most mammals. Human spermatozoa are exceptional. Some survive when ampoules containing untreated semen are frozen rapidly by immersion in liquid nitrogen at $-196^{\circ} \mathrm{C}$. Spermatozoa of the bull and other mammals are killed by rapid cooling either above or below zero. Physico-chemical changes in the cell membrane may be responsible. Ultra-rapid cooling might cause instantaneous formation of minute intra- and extra-cellular ice crystals. Slow cooling results in growth outside the cells of larger crystals which might be less destructive; simultaneously, however, the concentration of salts rises and the spermatozoa are pickled in strong brine. Glycerol buffers the salts during freezing and permits slow cooling to avoid thermal shock. Other neutral solutes act similarly, but glycerol is unique in its lack of toxicity in high concentrations at low temperatures. The optimum initial concentration of glycerol is approximately 10 per cent for protecting bull spermatozoa, but varies for sperm of other species according to their electrolyte sensitivity and is 0-5 per cent in human and 30 per cent in rabbit semen. The motility of glycerol-treated spermatozoa of ram, boar and rabbit is high after freezing, but the fertility of the thawed semen, assessed by artificial insemination, has so far been reduced or abolished 
in these species. Human pregnancies have been reported in the United States following insemination of glycerol-treated frozen semen ${ }^{4}$, but no critical experiment has been or is likely to be carried out in Great Britain. The fertilizing capacity of bull semen is not impaired by addition of glycerol and prolonged storage at $-79^{\circ}$ or $-196^{\circ} \mathrm{C}$., as judged by the proportion of cows which become pregnant and the millions of normal calves already born as the result of its use. Semen of the 1952 Cambridge vintage, including samples from a bull now dead three years, still show little, if any, reduction of activity or fertilizing capacity. Farmers are already exploiting a wide choice of bulls not previously at their service. When results of progeny tests on young bulls are obtained, large stocks of semen from the best sires will be available locally and for export. Great improvements in cattle are anticipated throughout the world. Eventually, perhaps, the technique will be applicable to other farm animals.

A wide variety of other mammalian cells and tissues can now be frozen and stored without loss of viability in media containing glycerol at low temperatures. The story of how bone marrow came to be preserved in this way was told by Dr. D. W. H. Barnes. The starting-point was Jacobson's discovery in $1950^{5}$ that mice could be saved from death after lethal doses of X-rays if, afterwards, fragments of infantile mouse spleen were inserted intraperitoneally. The explanations proposed were either that a chemical agent from spleen protected tissues sensitive to irradiation or that hæmopoietic cells from the implanted tissue repopulated the bone marrow, which would have been totally destroyed by the doses given. The report by Lorenz ${ }^{6}$ that marrow from guinea pigs would protect mice of certain strains boosted the humoral theory. However, Barnes and Loutit had evidence that any treatment which killed the splenic cells also abolished their protective effect. One such treatment unlikely to harm a chemical agent was storage at $+4^{\circ}$ or at $-15^{\circ} \mathrm{C}$. Splenic tissue was therefore treated with glycerol and cooled to $-79^{\circ} \mathrm{C}$. by the method used for preserving the viability of ovarian tissue. When the material was thawed and injected into mice after irradiating them with the lethal dose of $950 \mathrm{r}$., the proportion of survivors was as high as in the control group treated with fresh spleen. There was no loss in potency of tissue after 83 days at $-79^{\circ} \mathrm{C}$. Rat bone marrow was then found to be effective in treating irradiated mice, and Barnes observed an early regeneration of hæmopoietic tissue. There are distinctive differences between the chromosomes of the mouse and the rat, which enabled Ford and Hamerton to demonstrate large numbers of dividing rat cells in the marrow, spleen and lymph glands of the treated mice? Radiation had destroyed the ability of the animals to react against the foreign cells which had therefore colonized the damaged hæmo- and lympho-poietic tissues. These mice also accepted grafts of rat skin, which survived indefinitely and were recognized by the colour and length of the hairs. Rat bone marrow which had been stored in the frozen state gave results as good as those obtained with fresh marrow.

Hitherto, the concept of animals composed of tissues from two or more species has belonged to mythology. The modern chimæra, produced after irradiation, is a brilliant departure from conventional biology. It is gratifying that the use of low temperatures should have contributed to its recognition. Hopes can now be renewed of establishing banks of frozen but viable bone marrow and other tissues to replace deficient or disordered tissues in man.

Re-animation of dead and frozen animals and man is another concept with origins in antiquity. Claims to have witnessed or effected such resurrections have been made and refuted many times in ancient, medieval and modern times. Superficial tissues can be frozen without altering the internal temperature or endangering the life of the animal as a whole, although frostbite may cause local death and loss of extremities. Man and other mammals become anæsthetized when cooled by as little as 10-15 deg. C. Claude Bernard showed that guinea pigs recovered when rewarmed from internal temperatures of $18^{\circ}$, but at $16^{\circ} \mathrm{C}$. breathing and heart beats stopped and they died. Cooling to approximately this degree was lethal to all non-hibernators. The demonstration by Andjus $^{8}$ that rats could be resuscitated from body temperatures between $0^{\circ}$ and $2^{\circ} \mathrm{C}$. and after $1 \mathrm{hr}$. of respiratory and circulatory arrest necessitated revision of criteria of death and opened new possibilities for therapeutics and experimentation. Dr. A. U. Smith has cooled golden hamsters until breathing and heart beats were at a standstill and then immersed them in baths at $-5^{\circ} \mathrm{C}$. to reduce the deep body temperature below zero. About 75 per cent of the animals froze progressively while the deep body temperature remained at the freezing point of plasma $\left(-0.6^{\circ} \mathrm{C}\right.$.). At the end of an hour the proportion of water converted to ice was 90 per cent in the subcutaneous tissues, 60 per cent in the brain and 50 per cent in the entire body. Nevertheless, hamsters frozen for periods up to $1 \mathrm{hr}$. recovered fully after rewarming the whole body with diathermy and giving artificial respiration. Frost-bite only occurred if the extremities had been bent in the frozen state. About 25 per cent of the hamsters became supercooled and were resuscitated completely from body temperatures as low as $-5 \cdot 0^{\circ} \mathrm{C}$. Those which crystallized spontaneously after supercooling to temperatures below $-3 \cdot 0^{\circ} \mathrm{C}$. did not revive. Difficulties arose when rabbits and small primates (Galago crassicaudatus) were frozen at and rewarmed from body temperatures below $0^{\circ} \mathrm{C}$. Heart beats, breathing and spontaneous movements were usually regained after thawing, but the animals died a few hours later, showing that present techniques are inadequate. Experiments on freezing isolated uteri and hearts suggest that eventually it may be possible to perfuse the whole mammal with glycerol and revive it after freezing at temperatures as low as those used for storing isolated cells and tissues. Much remains to be done before these results could be applied to man.

It was remarkable that this symposium should have assembled so much information not discussed at recent conferences on low-temperature biology $y^{9,10}$. Many new problems were also posed, some of which, it is hoped, will be solved by scientists of other disciplines and of the rising generation who had gathered at the British Association's meeting in Glasgow.

AUDREY U. SMITH

${ }^{1}$ Asahina, E., and Aoki, K., Nature, 182, 327 (1958).

${ }^{2}$ Scholander, P. F., et al., J. Cell. Comp. Physiol., 42, supp. 1, 1 (1953).

${ }^{3}$ Polge, C., Smith, A. U., and Parkes, A. S., Nature, 164, 666 (1949).

4 Bunge, R. G., and Sherman, J. K., Nature, 172, 767 (1953).

${ }_{5}^{5}$ Jacobson, L. O., et al., J. Lab. Clin. Med,, 37, 683 (1951).

- Lorenz, E., et al., J. Nat. Cancer Inst., 12, 197 (1951).

'Ford, C. E., et al., Nature, 177, 452 (1956).

${ }^{8}$ Andjus, R. K., and Smith, A. U., J. Physiol., 123, 66P (1954).

${ }^{9}$ Proc. Roy. Soc., B, 147, 424 (1957).

${ }^{10}$ Nature, 181, 1694 (1958). 